\title{
ANALISIS PENGUKURAN KINERJA PERUSAHAAN PT. XYZ DENGAN MENGGUNAKAN METODE BALANCED SCORECARD
}

\author{
Yakobus Teofilus \\ Program Studi Magister Manajemen Universitas Tarumanagara \\ jakobus.teofilus@gmail.com \\ Anas Lutfi \\ Program Studi Magister Manajemen Universitas Tarumanagara \\ Masuk : 17-11-2017, revisi : 05-12-2017 diterima untuk diterbitkan : 05-12-2017
}

\begin{abstract}
The business environment today in Indonesia is shifting to a whole new level of measuring its performances. Rather than only one financial perspective which causes evaluating the customer's needs, the internal processes, and the human resources separately, the company must have a comprehensive tool to link its vision and missions into strategies that can be implemented and measured. This research aims to analyze and explore the linkage of vision, missions into strategy map, also a measurement of performances at the company using SWOT analysis, TOWS analysis, IE matrix, and Balanced Scorecard analysis. This research presents that balanced scorecard measurement could give benefits by exploring the nonfinancial perspectives that enable the company to create strategic alignment between strategic objectives that link the company's vision and missions into strategic outcomes and performance driver so can boost the company's performance.
\end{abstract}

Keywords: Balanced Scorecard, A Measurement Of Performances, Strategic Alignment, Strategic Objectives, Strategy Map

\section{PENDAHULUAN}

Pertumbuhan sektor properti dalam satu dekade terakhir telah mengalami pasang surut, diawali pada tahun 2008 dimana perekonomian negara Republik Indonesia terkena imbas dari krisis subprime mortgage dari negara Amerika yang juga mempengaruhi sektor properti, namun perekonomian Indonesia sudah lebih tangguh dibanding pada satu dekade sebelumnya yakni tahun 1998, tahun - tahun berikutnya sektor properti mulai merangkak naik bahkan disinyalir mencapai puncaknya pada tahun 2013, namun seiring pertumbuhan signifikan sektor properti pada sisi perbankan mengimbangi hal tersebut, dapat dilihat pada pertumbuhan BI Rate dari $6,75 \%$ pada tahun 2009 menjadi $7,75 \%$ pada tahun 2015 yang sangat berpengaruh pada kredit kepemilikan sektor properti, tahun berikutnya pertumbuhan properti masih dinilai lambat, namun tahun ini sektor properti mulai diyakini merangkak naik, sehingga banyak perusahaan properti mulai menggarap dan menjual produknya, sejalan dengan maraknya pergerakan terebut perusahaan pengembang wajib memiliki strategi yang tang tepat dan berdaya guna.

PT. XYZ adalah perusahaan pengembang properti yang telah cukup lama beroperasi, yakni sejak 1993. Namun sistem pengukuran kinerjanya masih menggunakan model pengukuran finansial konvensional. Hal ini menyebabkan perusahaan memiliki hambatan mengukur kinerja bisnis karena pengukuran aset non finansial tidak pernah dilakukan, serta sulit untuk menerjemahkan dan mendistribusikan hubungan visi, misi, dan nilai dasar, serta sasaran jangka panjangnya kepada setiap elemen perusahaan. Sehingga permasalahan tersebut apabila dibiarkan, dapat menghambat pertumbuhan dan daya saing perusahaan dalam mencapai tujuan utamanya.

Saat ini PT. XYZ sudah dikelola oleh generasi kedua pemilik, walaupun pertumbuhan secara pengukuran finansial meningkat, namun masih terdapat kesenjangan yang cukup 
dirasakan pada masing - masing elemen perusahaan dimana seperti berjalan sendiri tanpa arah yang jelas, hanya melakukan instruksi tanpa mengetahui untuk apa divisi tersebut melakukan hal tersebut dan tanpa pengukuran yang konsisten.

\section{TELAAH KEPUSTAKAAN}

Salem, et al. (2012) menyampaikan kesimpulan bahwa "Sejak dekade terakhir, sistem pengukuran kinerja telah menjadi kebutuhan legislatif pada sektor swasta maupun publik. Perusahaan selalu mencari perangkat pengukuran kinerja yang efektif. Namun sangat disayangkan, banyak sistem pengukuran kinerja memiliki kekurangan khususnya terhadap pengukuran lingkungan dan sosial. Membandingkan Balanced Scorecard dengan sistem pengukuran kinerja lainnya membuktikan bahwa Balanced Scorecard memiliki kemampuan lebih dari sistem pengukuran kinerja lainnya terutama karena Balanced Scorecard mampu menampilkan dimensi yang berbeda dari kinerja itu sendiri”.

Sehingga mengutip Sipayung (2009) utarakan bahwa "Keberhasilan atau kegagalan perusahaan tidak dapat dimotivasi atau di ukur dalam ukuran jangka pendek oleh model akuntansi keuangan tradisional. Karena model finansial tradisional tersebut, pada umumnya hanya mengukur peristiwa masa lalu, bukan mengukur kinerja investasi yang akan ditanamkan dalam berbagai kapabilitas untuk menghasilkan nilai masa depan”.

Pendapat ilmiah mengenai sistem pengukuran kinerja dijelaskan oleh Neely et al. (2003) "Sistem pengukuran kinerja didefinisikan sebagai seperangkat ukuran yang digunakan untuk menjadikan aksi-aksi dari efektivitas dan efisiensi sebagai data kuantitatif".

Kaplan dan Norton (1996) menyatakan mengapa Balanced Scorecard sangat penting dalam strategi bisnis, adalah sebagai berikut:

1. Balanced Scorecard mampu menjelaskan visi masa depan perusahaan kepada seluruh elemennya. Hal ini menciptakan pemahaman bersama dari seluruh elemen perusahaan terhadap visi masa depan perusahaan.

2. Balanced Scorecard menciptakan model strategis menyeluruh yang memungkinkan seluruh karyawan melihat bagaimana mereka berkontribusi terhadap keberhasilan organisasi. Tanpa hubungan ini, karyawan dan divisinya hanya menunjukkan kinerja lokal tetapi belum tentu bahkan cenderung tidak memberikan kontribusi terhadap pencapaian sasaran strategis perusahaan.

3. Balanced Scorecard fokus pada upaya perubahan. Ketika sasaran dan pengukuran yang tepat guna ditemukan, maka kemungkinan keberhasilan pelaksanaannya akan sangat besar.

Sehubungan dengan beberapa pernyataan di atas, penulis tertarik untuk mendalami sistem pengukuran kinerja perusahaan melalui pendekatan Balanced Scorecard yang akan dituangkan dalam penelitian dengan judul "Analisis Pengukuran Kinerja perusahaan PT. XYZ dengan menggunakan Metode Balanced Scorecard".

\section{Pokok Masalah}

Pokok masalah yang akan dibangun pada penelitian tesis ini adalah sebagai berikut:

1. Bagaimana analisis SWOT terhadap posisi strategis perusahaan?

2. Bagaimana analisis matriks TOWS dan alternatif rumusan strategisnya?

3. Apa sasaran strategis dari masing-masing empat perspektif Balanced Scorecard yang seharusnya perusahaan miliki untuk meningkatkan kinerjanya?

4. Bagaimana pengukuran Balanced Scorecard memperlihatkan kinerja perusahaan?

\section{METODE PENELITIAN}

Metode analisis data dalam penelitian ini menggunakan metode dengan eksplanasi deskriptif, dimana setelah data diperoleh keseluruhannya lalu ditindaklanjuti dengan langkah berikutnya yakni dianalisis untuk mendapatkan hasil yang baik, serta dapat dimanfaatkan untuk merumuskan strategi baru yang meningkatkan kinerja perusahaan. 
Langkah-langkah dalam menganalisis data, adalah sebagai berikut:

1. Memeriksa data yang diperoleh apakah sudah benar sesuai kriteria yang dibutuhkan atau belum.

2. Identifikasi data, yakni menggunakan data sesuai dengan bentuk dan keperluannya.

3. Interpretasi dan analisis data, yakni menetapkan ukuran dan metode yang diperlukan untuk mengolah data yang diperoleh.

4. Pengambilan kesimpulan, yakni berdasarkan hasil analisis dapat ditarik kesimpulan. Metode analisis yang digunakan pada penelitian ini adalah:

1. Analisis SWOT dilanjuti dengan analisis External Factor Evaluation (EFE) dan Internal Factor Evaluation (IFE), serta analisis matriks IE untuk mengetahui posisi perusahaan saat ini dan tema strategis.

2. Analisis Pair-Wise Comparisons untuk menentukan bobot EFE dan IFE, bobot balanced scorecard beserta bobot indikator penggeraknya.

3. Analisis Matriks TOWS terhadap hasil analisis SWOT untuk mendapatkan indikator strategis.

4. Analisis Balanced Scorecard untuk mendapatkan sasaran strategis, indikator hasil, dan indikator penggerak yang disertai bobot untuk mengukur kinerja perusahaan.

\section{ANALISIS DAN BAHAN TEMUAN}

Langkah awal dalam menyusun strategi perusahaan yang dituangkan dalam Balanced Scorecard PT. XYZ, penulis terlebih dahulu melakukan analisis faktor-faktor eksternal dan internal dengan menggunakan metode analisis SWOT, analisis External Factor Evaluation (EFE) dan Internal Factor Evaluation (IFE), serta analisis matriks TOWS untuk dapat mengidentifikasi faktor-faktor tersebut kemudian diolah menjadi sebuah strategi bisnis.

Setelah melakukan identifikasi faktor - faktor utama yang terdapat pada masing - masing elemen SWOT, analisis dilanjutkan dengan melalui analisis matriks IE, dimana setiap faktor faktor utama eksternal dan internal dari analisis SWOT diberi bobot dan rating untuk menentukan posisi perusahaan pada sektor industri saat ini. Hasil dari analisis EFE dan IFE adalah posisi perusahaan berada pada sel ke-V matriks IE dengan tema strategis yang disarankan yakni penetrasi pasar dan pengembangan produk.

Dilanjuti dengan analisis balanced scorecard yang akan membahas detil dari masingmasing perspektif untuk menghasilkan indikator hasil dan indikator penggeraknya. Pembahasan tersebut adalah sebagai berikut:

a. Perspektif Keuangan

Perspektif keuangan PT. XYZ memiliki bobot sebesar 32\%, dengan indikator penggerak sebagai berikut: Total pendapatan, Margin laba kotor, Margin laba bersih, Rasio biaya operasional, Perputaran akun piutang, dan Rata - rata periode kolektif. Melihat data laporan dan neraca, hasil analisis indikator penggerak dapat dilihat dari pendapatan usaha mengalami pertumbuhan yang cukup baik sebesar 138,26\% dibanding tahun sebelumnya, margin laba kotor yang mengalami penurunan sebesar 98,76\% diikuti oleh margin laba bersih sebesar 95,96\%, sementara rasio biaya operasional mengalami kenaikan sebesar $0,12 \%$ yang sebenarnya memberi sinyal kurang baik, perputaran piutang mengalami pertumbuhan sebesar $0,42 \%$, dan periode koleksi rata-rata yang mengalami percepatan dari rata-rata koleksi selama 246 hari menjadi rata - rata 189 hari.

b. Perspektif Pelanggan

Analisis untuk perspektif pelanggan diawali oleh tingkat pertumbuhan jumlah pelanggan yang berhasil menambah sebesar $8,00 \%$ diakhir 2013, serta mengalami peningkatan di akhir tahun 2014 sebesar 11,48\%. Sementara pertumbuhan jumlah pelanggan baru sebagai penanda bahwa perusahaan telah memperluas jangkauan pangsa pasar berhasil meningkat diakhir 2013 sebesar 7,42\%, diikuti akhir tahun 2014 yang bertambah sebesar $10,52 \%$. Pertumbuhan jumlah pelanggan lama menandakan bahwa 
adanya kepuasan dari pelanggan sehingga pelanggan membeli ulang produk perusahaan bertumbuh signifikan di akhir 2013 sebesar 12,37\%, serta bertumbuh 18,26\% di akhir 2014. Dilanjutkan dengan indeks kepuasan pelanggan yang diperoleh dari kuesioner pelanggan memperlihatkan hasil baik di tahun 2013, dimana indeks kepuasan mencapai angka 3,78 dari skala $1-5$, namun seiring dengan pertumbuhan jumlah pelanggan maka indeks kepuasan pelanggan pun menurun menjadi 3,69.

c. Perspektif Proses Internal

Pengukuran kinerja pada perspektif proses internal balanced scorecard memerlukan adanya proses inovasi, operasional, dan layanan yang mendekati kebutuhan pelanggan, Pengukuran kinerja inovasi diukur melalui peningkatan produktivitas aset, diukur dari rasio luas aset produktif per karyawan perusahaan yang menggambarkan semakin besar luas aset per meter persegi terhadap satu karyawan semakin besar kinerja yang dihasilkan. Penggerak untuk kinerja tersebut adalah rasio aset terjual per karyawan dan rasio aset terencana per karyawan. Pada tahun 2013 PT. XYZ berhasil membukukan aset terjual seluas $50.030 \mathrm{~m} 2$ dan aset terencana seluas $62.537 \mathrm{~m} 2$ dengan jumlah karyawan sebanyak 133 orang, sehingga rasio aset terjual per karyawan adalah $376 \mathrm{~m} 2$ terjual per kayawan dan $470 \mathrm{~m} 2$ terencana per karyawan. Di tahun 2014 tercatat aset terjual seluas $63.852 \mathrm{~m} 2$ terjual dan $87.988 \mathrm{~m} 2$ terencana dengan jumlah karyawan yang meningkat menjadi 138 orang, sehingga rasio rasio menjadi $463 \mathrm{~m} 2$ terjual per karyawan dan $638 \mathrm{~m} 2$ terencana per karyawan, sementara rasio biaya kerja tambah/kurang terhadap biaya kontrak pada tahun 2013 tercatat sebesar 0,5\% dan apada tahun 2014 meningkat menjadi $0,63 \%$. Sementara rasio serah terima pelanggan mengalami penurunan dari rata - rata tepat serah terima sebesar 94,94\% di tahun 2013 menjadi 93,17\% di tahun 2014. Sementara penyelesaian rata - rata komplain konstruksi juga meningkat dari rata - rata 2,63 hari di tahun 2013 menjadi 2,53 hari di tahun berikutnya, hasil kepuasan pelanggan pada tahun 2013 didapat sebesar 3,63 namun menurun di tahun 2014 menjadi 3,58.

d. Perspektif Pembelajaran dan Pertumbuhan

Pengukuran kinerja pada perspektif pembelajaran dan petumbuhan fokus kepada tiga hal utama, yakni kompetensi strategis, teknologi strategis, lingkungan kerja yang aktif produktif. Tahun 2013 PT. XYZ mencatat total jam pelatihan adalah 90 puluh jam, dengan jumlah karyawan sebanyak 133 orang maka rata - rata jumlah jam pelatihan per karyawan selama satu tahun adalah hanya 40 menit, hal ini diperburuk ditahun 2014 dimana jumlah jam pelatihan hanya 77 jam sementara jumlah karyawan meningkat menjadi 138 karyawan, sehingga rata - rata jam pelatihan per karyawan hanya 33 menit saja. Penggerak kedua adalah persentase jumlah kehadiran karyawan yang mengikuti pelatihan dan pembelajaran, tercatat pada tahun 2013 jumlah keikutsertaan karywan dalam pelatihan dan pembelajaran hanya $93,23 \%$ kemudian semakin menurun menjadi 91,30\% ditahun 2014. Sementara pengelolaan disiplin karyawan diukur dari jumlah jam kerja yang seharusnya digunakan untuk produktivitas namun hilang karena karyawan terlambat masuk kerja, pulang lebih cepat, dan alpa, ditahun 2013 PT. XYZ mencatat kehilangan jam kerja sebesar 1 jam 19 menit rata-rata per karyawan, diikuti bertambahnya kehilangan jam kerja tersebut ditahun 2014 sebesar 1 jam 23 menit ratarata per karyawan.

\section{KESIMPULAN DAN SARAN \\ Kesimpulan}

Berdasarkan hasil analisis dan pembahasan pada bab sebelumnya, penulis membuat beberapa kesimpulan dan saran dengan penjabaran sebagai berikut:

1. Hasil analisis SWOT dan matriks IE, PT. XYZ mempunyai beberapa faktor internal dan eksternal yang menggambarkan posisi perusahaan saat ini berada sel ke-V yang berarti 
tema startegis yang dapat dijalankan oleh perusahaan adalah melakukan penetrasi pasar dan mengembangkan produknya.

2. Hasil dari analisis matriks TOWS didapat beberapa rumusan startegis, yakni:

a. Memanfaatkan peluang melalui kerjasama dengan perusahaan properti asing, pemerintah setempat, dan lembaga keuangan.

b. Melakukan inovasi - inovasi pada proses internal untuk mengembangkan produk dan mengelola efektivitas produksi.

c. Mengembangkan sistem pengukuran kinerja yang menyeluruh.

d. Melengkapi kompetensi dari setiap elemen perusahaan agar produktivitas karyawan dapat meningkat.

3. Dari analisis balanced scorecard, sasaran strategis untuk masing - masing perspektif adalah sebagai berikut:

a. Perspektif keuangan.

Peningkatan laba ditempatkan paling utama untuk menjadi tolok ukur kinerja perusahaan karena berhubungan langsung dengan peningkatan kesejahteraan para shareholder. Peningkatan pendapatan telah dicapai oleh PT. XYZ, namun margin laba yang dicatat malah menurun, hal ini sangat dipengaruhi oleh pengelolaan efisiensi biaya. Pengukuran kinerja produktivitas pada perspektif keuangan adalah untuk melihat kinerja pengelolaan efisiensi biaya dan perputaran aset yang menjadi piutang dan periode kolektif piutang yang juga berhubungan peningkatan nilai kesejahteraan shareholder. Kinerja produktivitas sudah baik, namun karena kurangnya pengelolaan efisiensi biaya maka berdampak negatif kepada profitabilitas.

b. Perspektif pelanggan.

Diyakini dengan semakin bertambahnya jumlah pelanggan maka semakin besar pendapatan perusahaan, baik melalui pelanggan baru maupun pelanggan lama. Dengan pengembangan produk yang lebih compact, PT. XYZ berhasil menambah pelanggan, namun jika dilihat lebih dalam lagi, porsi pelanggan lama lebih mempunyai pengaruh dibanding dengan pertumbuhan pelanggan baru, yang dapat berarti PT. XYZ kurang memperluas pangsa pasarnya. Seiring dengan bertambahnya jumlah pelanggan, kepuasan pelanggan pun harus tetap dikelola dan dijaga dengan baik agar tidak kehilangan pelanggan. Kepuasan pelanggan adalah salah sattu faktor kunci untuk memperluas penetrasi pasar, dalam hal ini PT. XYZ tidak menjaga nilai kepuasan pelanggannya.

c. Perspektif proses internal.

Aset utama perusahaan properti adalah ketersediaan lahan untuk direncanakan dan dijual, sehingga peningkatan produktivitas aset per karyawan menjadi penggerak utamanya. PT. XYZ sudah konsisten untuk meningkatkan aset lahan yang terjual dan direncanakan untuk dijual. Beberapa faktor kunci sukses perusahaan properti adalah pengelolaan efisiensi biaya, ketepatan waktu serah terima, dan kecepatan merespon produk yang memerlukan perbaikan. Dalam hal ini PT. XYZ masih belum mengelola dengan baik. Dikarenakan produk yang sudah dibeli oleh pelanggan akan dipakai dalam waktu yang lama, serta lingkungan tempat dimana produk properti tersebut juga harus dikelola, maka kepuasan pelanggan purna jual juga perlu diperhatikan. Seiring dengan bertambahnya pendapatan perusahaan, PT. XYZ pada faktor penggerak ini kurang konsisten menjaga kepuasan pelanggan purna jual.

d. Perspektif pertumbuhan dan pembelajaran.

Pengelolaan kompetensi strategis digerakkan oleh peningkatan kompetensi sumber daya manusianya, dengan memberikan pelatihan yang tepat dan jumlah jam pelatihan yang cukup akan memberikan peningkatan kompetensi karyawannya sehingga mempengaruhi produktivitas perusahaan. PT. XYZ telah memberikan beberapa pelatihan dengan tema yang menarik, namun jumlah jam pelatihan tersebut 
belum mencukupi bahkan menurun. Pada jaman ini ketika pemanfaatan teknologi juga menjadi salah satu faktor kunci sukses dunia bisnis, maka diperlukan suatu ukuran dimana perusahaan sudah memanfaatkan teknologi saat ini dan mendatang. PT. XYZ sudah memanfaatkan teknologi dengan mentransformasikan prosedur kedalam perangkat lunak, namun peningkatannya tidak dijaga sehingga menurun. Pada lingkungan kerja juga perlu diperhatikan untuk menjaga dinamika produktivitas perusahaan, dimana jika karyawan merasa puas berada diperusahaan tersebut maka produktiitas pun akan meningkat. Pt. XYZ belum memperhatikan perspektif ini, sehingga kinerja perusahaan walaupun baik namun apabila kinerja perspektif ini meningkat pasti menambah nilai kinerja keseluruhan keempat perspektif.

4. Analisis Balanced Scorecard dalam mengukur kinerja perusahaan terbukti efektif, dimana pengukuran kinerja dapat mendalam sampai kepada masing - masing perspektif, hasil dari perspektif keuangan berada pada posisi $35,74 \%$ dibanding bobotnya sebesar $32 \%$, diikuti oleh perspektif pelanggan yang juga mencatat kinerja sebesar $31,11 \%$ dari bobotnya sebesar $22,5 \%$, lanjut ke perspektif proses internal yang juga mencatat kinerja baik sebesar $26,76 \%$ dari bobotnya sebesar $25,5 \%$, ketiga perspektif tersebut memiliki kinerja baik, namun pada perspektif pembelajaran dan pertumbuhan kinerja perusahaan tidak mencapai bobot kinerja $20 \%$, atau hanya tercatat sebesar $18,18 \%$, hal ini mengakibatkan kinerja perusahaan hanya sebesar 111,79\%.

\section{Saran}

Berdasarkan beberapa simpulan diatas, berikut ini adalah saran yang dapat diberikan kepada perusahaan:

1. PT. XYZ disarankan untuk segera menggunakan pengukuran kinerja dengan metode balanced scorecard ini, agar kinerja perusahaan dapat berimbang disetiap perspektifnya, dan penerapannya pun disarankan tidak hanya pada level top management saja seperti direksi, general manager, dan manager divisi, tetapi juga dapat diikutsertakan sampai kepada seluruh karyawan.

2. Melalui pengukuran kinerja balanced scorecard ini perusahaan dapat menentukan target setiap tahunnya terhadap masing- masing indikator penggerak untuk meningkatkan kinerjanya.

3. Untuk dapat menjaga konsistensi pelaksanaan pengukuran kinerja balanced scorecard tersebut sebaiknya dibentuk suatu tim pelaksanaan dan pengawasan yang akan mengelola hasil pengukurannya.

4. Secara berkala sesuai dengan pertumbuhan, perusahaan wajib melakukan evaluasi dan pembaharuan terhadap indikator - indikator kinerja balanced scorecard.

\section{DAFTAR KEPUSTAKAAN}

Anthony, A., et al. (1995). Management Accounting (International Edition). New Jersey England Cliffs: Prantice-Hall International Inc.

Badjuri, A., \& Yuwono, T. (2002). Kebijakan Publik: Konsep dan Strategi. Semarang: Universitas Diponegoro.

Banker, R. D., Chang, H., \& Pizzini, M. J. (2004). The balanced scorecard: Judgemental effects of performance measures linked to strategy. The Accounting Review, 79(1), 1-23.

Bastian, I. (2010). Akuntansi Sektor Publik: Suatu Pengantar (Edisi Ketiga). Jakarta: Erlangga.

David, F. R., \& Forest, R. D. (2013). Strategic Management: Concepts and Cases: A Competitive Advantage Approach. Boston: Pearson.

Dess, G., Lumpkin, G. T., Eisner, A., \& McNamara, G. (2012). Strategic Management: Text and Cases. New York: McGraw - Hill Education.

Kaplan, R. S., \& Norton, D. P. (1996). The Balanced Scorecard: Translating Strategy into Action. Boston: Harvard Business School Press. 
Kaplan, R. S., \& Norton, D. P. (1992). The balanced scorecard - measure that drive performance. Harvard Business Review, January-February, 71-79.

Kaplan, R. S., \& Norton, D. P. (1996). Using the balanced scorecard as a strategic management system. Article of Harvard Business Review.

Mardiasmo. (2009). Akuntansi Sektor Publik. Yogyakarta: Andi Offset.

Mulyadi. (2001). Akuntansi Manajemen: Konsep, Manfaat dan Rekayasa. Jakarta: Salemba Empat.

Mulyadi. (2010). Sistem Akuntansi. Jakarta: Salemba Empat.

Neely, A. D., Bourne, M. C. S., Mills, J. F., \& Platts, K. W. (2003). Implementing performance measurement systems: a literature review. Int. J. Business Performance Management, $5(1), 1-24$.

Salem, M. A., Hasnan, N., \& Osman, N. H. (2012). Balanced scorecard: Weaknesses, strengths, and its ability as performance management system versus other performance management systems. Journal of Environment and Earth Science, 2(9), 1-10.

Sipayung, F. (2009). Balanced scorecard: pengukuran kinerja perusahaan dan sistem manajemen strategis. Jurnal Manajemen Bisnis, 2(1), 7-14.

Veithzal, R. (2008). Manajemen Sumber Daya untuk Perusahaan. Jakarta: PT. Raja Grafindo Persada.

Weihrich, H. (1982). The TOWS matrix - a tool for situational analysis. 15(2), 54-66. Long Range Planning 